\title{
manejo de Convolvuláceas em Dois Cultivares de Soja Semeada Diretamente sob Palha Residual de Cana Crua ${ }^{1}$
}

\author{
Convolvulaceae Management in Soybean Sown Directly Under Sugar-cane Straw
}

TIMOSSI, P.C. ${ }^{2}$ e DURIGAN, J.C. ${ }^{3}$

\begin{abstract}
RESUMO - A interferência de convolvuláceas na produtividade dos cultivares de soja (Coodetec 206 e Monsoy 6101) semeados diretamente sob a palha residual (12,8 $\left.\mathrm{t} \mathrm{ha}^{-1}\right)$ de cana crua foi estudada em relação aos manejos com o herbicida diclosulam $\left(0,035 \mathrm{~kg} \mathrm{ha}^{-1}\right)$ em mistura em tanque com glyphosate $\left(1,440 \mathrm{~kg} \mathrm{ha}^{-1}\right)$, aplicados na operação de dessecação da cana-de-açúcar, diclosulam isolado $\left(0,035 \mathrm{~kg} \mathrm{ha}^{-1}\right)$, em pré-emergência da cultura da soja, e fomesafen $\left(0,250 \mathrm{~kg} \mathrm{ha}^{-1}\right)$, em pós-emergência. Para isso, utilizou-se delineamento experimental de blocos casualizados, num esquema fatorial $2 \times 5$, com oito repetições. Observou-se pelos resultados que a utilização do herbicida diclosulam isoladamente e em mistura com o glyphosate promoveu controle eficaz das plantas daninhas. A infestação das cordas-de-viola não foi capaz de interferir negativamente nas características de crescimento das plantas, havendo apenas diferenças estatísticas entre os cultivares. As características de produção também não sofreram interferências negativas, exceto quanto à massa seca de 100 sementes no cultivar Monsoy 6101. Este cultivar Monsoy 6101 apresentou-se mais adequado para utilização dentro do período de renovação dos canaviais, por atingir o estádio $\mathrm{R}_{8}$ (colheita) nove dias antes.
\end{abstract}

Palavras-chave: Glycine max, Ipomoea spp., herbicidas residuais, plantas daninhas.

\begin{abstract}
A field trial was conducted to evaluate the chemical control of Convolvulaceae weeds in soybean fields under sugar-cane rotation. The sugar-cane was harvested without burning with a layer of straw on the soil surface. The herbicides evaluated were: diclosulam plus glyphosate $\left(0.035+1.440 \mathrm{~kg} \mathrm{ha} \mathrm{h}^{-1}\right.$, tank mix) during pre-crop and weed dissection, diclosulam alone $\left(0.035 \mathrm{~kg} \mathrm{ha}^{-1}\right)$ on soybean preemergence and fomesafen $\left(0.250 \mathrm{~kg} \mathrm{ha}^{-1}\right)$ on soybean postemergence. In the field the plots were arranged in a completely randomized block design, and the treatments in a 2x5 factorial design, the factors consisting of two soybean cultivars (Coodetec 206 and Monsoy 6101) and five weed management measures (weedy, weed free, diclosulam, fomesafen and diclosulam + glyphosate). The results showed that the weed densities were not sufficient to reduce soybean productivity. Diclosulam and its mixture with glyphosate provided good control of the convolvulaceae species: Ipomoea grandifolia, Ipomoea quamoclit and Merremia cissoides. The cultivar Monsoy 6101 was considered the most suitable for sugar-cane rotation due to its shorter cycle.
\end{abstract}

Keywords: Glycine max, Ipomoea spp., residual herbicide, weeds.

\section{INTRODUÇÃO}

A queimada da cana-de-açúcar será proibida no Estado de São Paulo, conforme esquema de restrições legais progressivas até o ano de 2021, em áreas com possibilidade de mecanização da colheita, e 2031, nas demais áreas (Decreto no 47.700 de 11.3.2003, que regulamenta a lei no 11.241 de 19-9-2002). Devido a essa nova realidade, a semeadura direta sob a palha vem assumindo grande importância nos seus sistemas de produção.

1 Recebido para publicação em 6.6.2005 e na forma revisada em 24.2.2006.

Parte da tese de doutorado apresentada à FCAV/UNESP, Jaboticabal-SP.

2 Eng.-Agr., D.S. em Produção Vegetal pela FCAV-UNESP, Via de acesso Paulo Donato Castellane, s/n, 14844-900 JaboticabalSP, <ptimossi2004@yahoo.com.br>; ${ }^{3}$ Prof. Titular do Dep. de Fitossanidade da FCAV/UNESP, <jdurigan@ fcav.unesp.br>. 
No que se refere ao comportamento das plantas daninhas, tem-se notado que em áreas de "cana crua" estão surgindo infestações de Euphorbia heterophylla e Ipomoea spp. (Martins et al., 1999). Segundo Pitelli \& Durigan (2001), o efeito físico da cobertura morta pode reduzir as chances de sobrevivência das plântulas de plantas daninhas com pequenas quantidades de reservas nas sementes, as quais podem não ser suficientes para lhes garantir a sobrevivência no espaço percorrido através da cobertura, até que tenha acesso à luz e inicie o processo de fotossíntese. Portanto, entre outras características, as espécies que possuírem sementes com grande quantidade de reservas terão maior probabilidade de perpetuar-se nesse novo sistema de produção.

O uso de herbicidas residuais sobre a palhada de cana-de-açúcar vem sendo considerado um dos maiores desafios no sistema de cana crua, pois são poucas as informações sobre a maioria dos produtos recomendados, no que diz respeito à retenção/travessia e, conseqüentemente, à ação deles. Diante das alterações provocadas pela mudança do sistema de colheita da cana-de-açúcar, faz-se necessária a adoção de um conjunto de novas técnicas culturais, pois, mesmo em baixas infestações, ocorrem problemas com algumas espécies de plantas daninhas, como Cyperus rotundus (Silva et al., 2003; Durigan et al., 2004), E. heterophylla (Martins et al., 1999) e Ipomoea spp. (Martins et al., 1999; Correia \& Durigan, 2004).

Com o aumento das áreas de cana-deaçúcar colhidas sem queima (cana crua), uma alternativa viável para o período de renovação dos canaviais é o cultivo da soja em semeadura direta. Para isso, é necessário o uso integrado de métodos químico e cultural para o controle de plantas daninhas na soja, após a semeadura direta sob a palha de cana-de-açúcar.

Uma prática já usada em áreas de semeadura direta de cereais, embora proibida por lei (MCT, 2002), é a mistura em tanque de herbicidas de manejo e residuais, visando eliminar plantas de cobertura e plantas daninhas já instaladas e, com isso, diminuir os custos de aplicação e controlar os fluxos de emergência ocorridos durante a fase inicial de desenvolvimento da cultura. No entanto, em áreas de renovação de canavial colhido mecanicamente no sistema de cana crua, são quase inexistentes os relatos sobre o tema.

O objetivo deste trabalho foi avaliar as formas de manejo de convolvuláceas, verificando a interferência na produtividade de dois cultivares de soja semeados diretamente sob a palhada de cana-de-açúcar colhida mecanicamente no sistema de cana crua, além da busca pelo cultivar mais adaptado ao programa de renovação desse tipo de canavial.

\section{MATERIAL E MÉTODOS}

O experimento foi instalado e conduzido no ano agrícola de 2003-2004, no município de Jaboticabal-SP, sobre solo caracterizado como Latossolo Vermelho, textura argilosa e relevo suave ondulado (Embrapa, 1999).

A fim de garantir a infestação homogênea de pelo menos uma espécie de corda-de-viola (Ipomoea grandifolia) na área experimental, houve necessidade de semeá-la. Para isso, removeu-se a palha das entrelinhas da canade-açúcar e, por meio de sulcos rasos (2 a $3 \mathrm{~cm}$ ) realizados com enxada, fez-se a semeadura, em densidades semelhantes, para todas as parcelas. Posteriormente, fez-se o retorno da palha para sua posição original, antes da dessecação das soqueiras de cana-de-açúcar. A área continha sementes de infestações naturais de Ipomoea quamoclit e Merremia cissoides.

A aplicação de glyphosate (360 g e.a. $\mathrm{L}^{-1}$ ), a 1,440 kg ha-1, para eliminação das soqueiras foi realizada 14 dias antes da semeadura. Cada parcela constou de três linhas de canade-açúcar, espaçadas de $1,4 \mathrm{~m}$ por $5 \mathrm{~m}$ de comprimento. No momento da aplicação havia umidade na superfície do solo, satisfatória para a ação do glyphosate, e as soqueiras estavam no estádio de seis a sete folhas, com 0,7 $\mathrm{m}$ de altura.

O delineamento experimental utilizado foi o de blocos casualizados, num esquema fatorial 2x5, com oito repetições. Constituíram os fatores os cultivares de soja (Coodetec 206, de ciclo semiprecoce, e Monsoy 6101, de ciclo precoce) e as formas de manejo utilizadas para controle das plantas daninhas (associação de diclosulam a $0,035 \mathrm{~kg} \mathrm{ha}^{-1} \mathrm{em}$ mistura em 
tanque com glyphosate a $1,440 \mathrm{~kg} \mathrm{ha}^{-1}$, aplicados no momento da operação de eliminação das soqueiras de cana-de-açúcar; diclosulam isolado a $0,035 \mathrm{~kg} \mathrm{ha}^{-1}$, aplicado em pré-emergência da soja; e fomesafen a $0,250 \mathrm{~kg} \mathrm{ha}^{-1}$, aplicado em pós-emergência, além de testemunhas mantidas no limpo, pela realização de monda, e infestada). Em cada parcela foram semeadas sete linhas de soja, espaçadas de $0,50 \mathrm{~m}$ e com $5 \mathrm{~m}$ de comprimento, buscan-

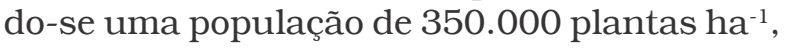
para ambos os cultivares.

As aplicações dos herbicidas (manejo e seletivos) foram feitas com pulverizador costal, a pressão constante de $246 \mathrm{kPa}$ (mantida por $\mathrm{CO}_{2}$ comprimido), utilizando-se barra com quatro bicos de jato plano e pontas XR1 1002, com consumo de calda equivalente a $200 \mathrm{~L} \mathrm{ha}^{-1}$.

O diclosulam foi aplicado sobre a palhada de cana-de-açúcar deixada sobre o solo, em pré-emergência das plantas daninhas e da soja, em duas modalidades, sendo a primeira em mistura com o glyphosate. Logo após a semeadura da soja foi aplicado o herbicida isoladamente. A aplicação, em pós-emergência, foi feita com o herbicida fomesafen, no estádio de 4 a 12 folhas das plantas daninhas e no estádio $\mathrm{V}_{3}$ (Fehr \& Caviness, 1977) da soja. Nas parcelas onde foi aplicado o diclosulam com atuação em pré-emergência foi necessário eliminar algumas plântulas de corda-de-viola que já haviam germinado, utilizando-se do herbicida de contato paraquat, na dosagem de $0,400 \mathrm{~kg} \mathrm{ha}^{-1}$.

Os dados referentes às condições atmosféricas pertinentes ao momento da aplicação dos herbicidas são apresentados na Tabela 1.

Os tratos culturais constaram de tratamento de sementes com thiram a $0,140 \mathrm{~kg} 100 \mathrm{~kg}^{-1}$ de sementes e inoculante turfoso (Bradyrhizobium japonicum) a $0,125 \mathrm{~kg} 100 \mathrm{~kg}^{-1}$ de sementes, além de micronutrientes (Mo 10\%, Co 4\%, B 2\% e Zn 7\%) a $0,200 \mathrm{~kg} 100 \mathrm{~kg}^{-1}$ de sementes. Foi feita adubação no sulco de semeadura, com $330 \mathrm{~kg} \mathrm{ha}^{-1}$ de termofosfato, e de cobertura, aos 30 dias após a semeadura (DAS), com $115 \mathrm{~kg} \mathrm{ha}^{-1}$ de $\mathrm{KCl}$, aplicado a lanço sobre a palha. Para o controle de pragas foram realizadas duas pulverizações, uma aos 45 e outra aos 70 DAS, com o inseticida metamidophos $\left(0,480 \mathrm{~kg} \mathrm{ha}^{-1}\right)$, visando controle de lagartas, besouros desfolhadores e percevejos. Houve necessidade de uma pulverização com o fungicida tebuconazole $\left(0,100 \mathrm{~kg} \mathrm{ha}^{-1}\right)$ para controle da ferrugem asiática, realizada no estádio $R_{5}$.

A densidade de convolvuláceas foi avaliada aos 28 DAS, através da contagem das plantas presentes na área útil da parcela. Aos 35, $42 \mathrm{e}$ 49 DAS, foi avaliado o controle das plantas daninhas promovido pelos herbicidas, realizando-se para isso a contagem das plantas emergidas, comparando-a à testemunha infestada, e extrapolando-se para escala percentual $(0 \mathrm{a}$ $100 \%)$.

Aos 42 DAS foi avaliado o estande inicial, quando se procedeu à contagem das plantas de soja por metro. Foram feitas contagens em seis metros nas linhas da área útil das parcelas. Para determinação do estande final, no momento da colheita de cada cultivar, foram feitas contagens em $12 \mathrm{~m}$ das três linhas centrais.

Aos 35 e 42 DAS, foram feitas cinco medições, ao acaso, das distâncias descobertas entre os dosséis, em duas entrelinhas das linhas centrais, com o uso de régua graduada, em centímetros. Avaliou-se também, aos 42 DAS, o crescimento das plantas de soja, através da medição da altura, em centímetros. Para isso, mediu-se a altura entre a superfície do solo e o topo do dossel das plantas de soja, seguindo a metodologia utilizada por Timossi \& Durigan (2002). Por ocasião da colheita,

Tabela 1 - Condições atmosféricas no momento da aplicação dos herbicidas complementares. Jaboticabal-SP, 2003-2004

\begin{tabular}{|l|c|c|c|c|c|}
\hline Aplicação & Data & Vento $\left(\mathrm{km} \mathrm{h}^{-1}\right)^{*}$ & UR ar $(\%)$ & T. ar $\left({ }^{\circ} \mathrm{C}\right)^{*}$ & Horário de Aplicação \\
\hline Glyphos. + diclos. & $11-11-03$ & 4 a 10 & 52 a 37 & 28 a 36,2 & $9 \mathrm{~h} 15-10 \mathrm{~h} 25$ \\
\hline Diclosulam & $25-11-03$ & 3 a 5 & 48 & 26 & 26,2 \\
\hline Fomesafen & $23-12-03$ & 2,5 a 5 & 86,6 & 23,3 & $10 \mathrm{~h}-10 \mathrm{~h} 10$ \\
\hline
\end{tabular}

* Valores obtidos no início e no final da aplicação. Obs.: Em todas as aplicações o solo se apresentava com umidade à superfície.

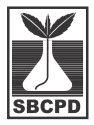


também foi feita a medição da altura em dez plantas de soja coletadas ao acaso. Nelas foram realizadas medições do comprimento, entre o colo e o final da haste principal. Também foram feitas avaliações das características ligadas à produção em dez plantas tomadas ao acaso, por parcela, como: altura de inserção da primeira vagem $(\mathrm{cm})$ e número de vagens por planta.

$\mathrm{Na}$ avaliação de intoxicação das plantas de soja ocasionada pelos herbicidas usados utilizou-se a escala de notas do EWRC (1964). As notas foram atribuídas, visualmente, aos 7 e 14 dias após a aplicação (DAA), em pós emergência, do fomesafen, ou seja, aos 35 e 42 DAS.

Ao final do ciclo de cada cultivar foram feitas avaliações visuais da porcentagem de cobertura vegetal promovida pela comunidade infestante, visando caracterizar o nível de dificuldade da colheita mecanizada da soja. Ainda, antecedendo a colheita dos cultivares de soja, foram efetuadas avaliações da porcentagem de acamamento das plantas, sendo consideradas como acamadas as plantas que apresentassem inclinação inferior a $45^{\circ} \mathrm{em}$ relação ao solo.

Na colheita, obteve-se a produção de grãos por unidade de área $\left(\mathrm{kg} \mathrm{ha}^{-1}\right)$, colhendo-se, manualmente, três linhas de quatro metros de comprimento cada. A produção por hectare foi obtida padronizando-se a umidade dos grãos para 13\%. Dos grãos colhidos, foram feitas amostragens para determinação da massa seca de 100 sementes (g) e classificação nas peneiras de números 16 e 15, baseando-se nas recomendações das Regras para Análise de Sementes (Brasil, 1980).

As informações atmosféricas durante o período experimental foram obtidas na Estação Agroclimatológica, localizada a $20 \mathrm{~km}$ da propriedade e pertencente à UNESP, campus de Jaboticabal. Os dados médios mensais de temperatura do ar $\left({ }^{\circ} \mathrm{C}\right)$ e precipitação pluviométrica $(\mathrm{mm})$ são apresentados na Tabela 2.

Os dados foram submetidos ao teste $\mathrm{F}$ da análise de variância e, para comparação das médias, utilizou-se o teste de Tukey a 5\% de probabilidade (Banzato \& Kronka, 1989). Quando necessário, foi utilizada a transformação dos dados em ARC SENSQRT $(\mathrm{x}+1,0)$.

Planta Daninha, Viçosa-MG, v. 24, n. 1, p. 91-98, 2006
Tabela 2 - Médias mensais de temperatura do ar e precipitação pluviométrica, coletadas durante o período de condução do experimento. Jaboticabal-SP, 2003-2004

\begin{tabular}{|c|c|c|}
\hline Mês & Temperatura média $\left({ }^{\circ} \mathrm{C}\right)$ & Precipitação $(\mathrm{mm})$ \\
\hline Novembro & 24,8 & 77,7 \\
\hline Dezembro & 25,8 & 210,2 \\
\hline Janeiro & 25,0 & 423,4 \\
\hline Fevereiro & 24,6 & 313,7 \\
\hline Março & 24,5 & 48,2 \\
\hline Abril & 23,9 & 94,3 \\
\hline
\end{tabular}

\section{RESULTADOS E DISCUSSÃO}

A dessecação das soqueiras de cana-deaçúcar bem feita é imprescindível para a implantação de culturas de sucessão na renovação do canavial. Quando ela é ineficaz, os rebrotes podem interferir nos tratos culturais, além de influenciarem negativamente as características de produção. Aos 14 DAA do glyphosate, o controle da soqueira foi, em média, de $68 \%$. Na última avaliação, aos 42 DAA, foi praticamente total $(99,1 \%)$. O bom controle inicial pode ter sido favorecido pelo uso de semeadora de grande porte, que promove desestruturação das touceiras, eliminando-as mais rapidamente.

Devido à presença de grande massa seca $\left(12,8\right.$ t ha $\left.^{-1}\right)$ de palha da cana-de-açúcar sobre o solo após a colheita mecanizada, as plantas daninhas da área ficaram restritas às convolvuláceas (gêneros Ipomoea e Merremia). Apesar da quantidade colocada de sementes de I. grandifolia, as plantas nasceram de forma esparsa. Azânia et al. (2002) demonstraram que $20 \mathrm{t} \mathrm{ha}^{-1}$ de palha de cana-de-açúcar das variedades SP79 2233 e RB83 5486, em relação à ausência de palha, reduziu em mais de $60 \%$ o número de plantas de $M$. cissoides, I. quamoclit, I. purpurea, I. grandifolia, I. hederifolia e I. nil. Segundo Pitelli \& Durigan (2001), plantas com características pioneiras, que não lograram sucesso adaptativo no sistema convencional, podem ser favorecidas com a semeadura direta e ter suas populações incrementadas. Dessa forma, é importante aferir a necessidade de integração do controle da comunidade infestante em estudo, por meio do uso de herbicidas. 
A densidade média de infestação de plantas daninhas por parcela estava em torno de 1,1 plantas $\mathrm{m}^{-2}$, com maior percentagem de plantas da espécie I. grandifolia.

Na Tabela 3 estão apresentados os resultados de controle obtidos sobre as convolvuláceas em estudo com o uso dos diferentes herbicidas. Ambas as modalidades de aplicação de diclosulam apresentaram controle semelhante e superior ao uso do fomesafen, indicando ser um produto com boa eficácia no controle das plantas daninhas presentes. Uma das preocupações em se utilizar o diclosulam em mistura em tanque com o glyphosate no momento da dessecação seria a diminuição da residualidade, prejudicando o controle durante o período total de prevenção à interferência das plantas daninhas na cultura da soja. No entanto, o nível de controle foi mantido durante as épocas avaliadas, não se diferenciando estatisticamente da aplicação em pré-emergência, isoladamente, após a semeadura. Rodrigues et al. (2002), trabalhando com glyphosate em mistura em tanque com os herbicidas residuais, imazapic e diclosulam, afirmaram que a diferença de eficácia na modalidade herbicida de manejosemeadura-herbicidas residuais foi pequena em relação à modalidade herbicida de manejo + residuais seguida de semeadura, com índices de controle das plantas daninhas em torno de
90\% aos 50 DAA em áreas de cobertura vegetal formada por milheto.

O diclosulam demonstrou evidências de ter boa solubilidade e baixa retenção, lixiviando através da camada de palha de cana-de-açúcar deixada sobre o solo e agindo eficazmente no controle das plantas daninhas em estudo, com boa ação residual.

O controle promovido pelo fomesafen, em pós-emergência, apresentou-se inferior, não atuando eficazmente, com rebrotes de plantas daninhas que apresentavam estádio de desenvolvimento superior ao recomendado, possibilitando também a emergência de novas plântulas durante o ciclo de vida da soja. Nas parcelas em que se aplicou o herbicida diclosulam também houve emergência de plântulas, mas, devido à sua ação nos pontos de crescimento das plantas (Rodrigues \& Almeida, 2005), estas morriam ou tinham seu crescimento paralisado. Os herbicidas aplicados em pós-emergência surgem como os mais promissores para o controle de plantas daninhas em semeadura direta, porém para o manejo de convolvuláceas apresentam baixa eficácia, devido à dormência das sementes, promovendo fluxos de emergência das plântulas em diferentes períodos. Nem sempre é possivel atingir todas as plântulas nos estádios recomendados, em face dos diferenciais de tempo nos fluxos de emergência.

Tabela 3 - Valores de F, coeficientes de variação (CV\%) e teste de Tukey aplicado às médias das porcentagens de controle, observados nas contagens de plantas feitas para corda-de-viola (Ipomoea grandifolia, I. quamoclit e Merremia cissoides), em diferentes dias após a semeadura (DAS). Jaboticabal-SP, 2003-2004

\begin{tabular}{|c|c|c|c|c|c|c|c|}
\hline & \multirow{2}{*}{ Variável } & \multicolumn{6}{|c|}{ Época de avaliação e controle de corda-de-viola } \\
\hline & & $35 \mathrm{DAS}^{1 /}$ & $\% \mathrm{C}$. & 42 DAS & $\% \mathrm{C}$. & 49 DAS & $\% \mathrm{C}$. \\
\hline \multirow{3}{*}{$\mathrm{F}$} & Cultivar (C) & $0,67^{\mathrm{ns}}$ & & $0,01^{\mathrm{ns}}$ & & $1,17^{\mathrm{ns}}$ & \\
\hline & Manejo (M) & $157,24 * *$ & & $88,03 * *$ & & $121,75 * *$ & \\
\hline & $\mathrm{C} \times \mathrm{M}$ & $0,16^{\mathrm{ns}}$ & & $0,01^{\mathrm{ns}}$ & & $0,24^{\text {ns }}$ & \\
\hline \multirow{2}{*}{ Cultivar (C) } & Coodetec 206 & 54,19 & $68,9^{3 /}$ & 53,20 & 67,0 & 50,00 & 59,7 \\
\hline & Monsoy 6101 & 56,04 & 71,9 & 53,45 & 67,0 & 47,24 & 53,5 \\
\hline DMS & & 4,49 & & 6,08 & & 5,11 & \\
\hline \multirow{5}{*}{ Manejo (M) } & Testemunha no limpo & $90,00 \mathrm{a}^{2 / 1}$ & 100,0 & $90,00 \mathrm{a}$ & 100,0 & $90,00 \mathrm{a}$ & 100,0 \\
\hline & Testemunha infestada & $5,74 \mathrm{~d}$ & 0,0 & $5,74 \mathrm{~d}$ & 0,0 & $5,74 \mathrm{~d}$ & 0,0 \\
\hline & diclosulam & $68,37 \mathrm{~b}$ & 83,4 & $67,07 \mathrm{~b}$ & 80,5 & $60,18 \mathrm{~b}$ & 72,4 \\
\hline & fomesafen & $47,38 \mathrm{c}$ & 53,2 & $40,21 \mathrm{c}$ & 44,4 & $32,50 \mathrm{c}$ & 32,7 \\
\hline & glyphosate + diclosulam & $64,10 \mathrm{~b}$ & 74,8 & $63,61 \mathrm{~b}$ & 76,2 & $54,69 \mathrm{~b}$ & 64,8 \\
\hline DMS & & 9,99 & ---- & 13,52 & $\begin{array}{ll}--- \\
\end{array}$ & 11,36 & $\begin{array}{ll}--- \\
\end{array}$ \\
\hline $\mathrm{CV}(\%)$ & & 18,2 & ---- & 25,5 & ---- & 23,5 & ---- \\
\hline
\end{tabular}

${ }^{1 /}$ Dados transformados em ARC SENSQRT $(\mathrm{x}+1,0) ;{ }^{2 /}$ médias seguidas da mesma letra, numa mesma coluna, não diferem entre si pelo teste de Tukey $(\mathrm{P}>0,05) ;{ }^{3 /}$ média dos dados originais. 
Os herbicidas aplicados e a densidade das plantas daninhas em estudo não interferiram negativamente nos estandes inicial e final, caracterizando boa seletividade dos produtos e baixa pressão competitiva das plantas daninhas. No entanto, foram constatadas diferenças estatísticas entre os cultivares, apesar das semelhantes porcentagens de germinação e números de sementes semeadas. Em média, o cultivar Monsoy 6101 apresentou inicialmente 19,4 (388.000 plantas ha-1) e 16,5 plantas $\mathrm{m}^{-1}$ (330.000 plantas ha-1) no momento da colheita, enquanto no Coodetec 206 esse número foi de 17,4 (348.000 plantas ha-1) e 15,6 plantas $\mathrm{m}^{-1}$ (312.000 plantas ha $\left.^{-1}\right)$, respectivamente. Os herbicidas utilizados para o controle das plantas daninhas e a densidade destas não foram capazes de afetar a distância descoberta entre dosséis e a altura das plantas de soja. Houve diferenças estatísticas apenas entre os cultivares, com maior crescimento de Monsoy 6101. A altura e a arquitetura das plantas de um determinado cultivar de soja são importantes no "fechamento" e conseqüente sombreamento do solo, evitando assim a germinação de sementes e o estabelecimento de várias espécies de plantas daninhas (Timossi \& Durigan, 2002). Aos 60 DAS, foi observado fechamento total das entrelinhas das plantas de soja do cultivar Monsoy 6101, enquanto para o Coodetec 206 isso não ocorreu durante o ciclo da cultura.

Aos 35 e 42 DAS constatou-se intoxicação leve a nula, proporcionada pelo fomesafen. Para o cultivar Coodetec 206 foram atribuídas notas 3, evoluindo para 1 na última avaliação. O cultivar Monsoy 6101 mostrou-se mais sensível, porém não ultrapassando os sintomas considerados leves pelo EWRC (1964). Dessa forma, foram atribuídas as notas 3,5 e 1,7 na última avaliação; isso mostra que os cultivares foram capazes de metabolizar as moléculas do fomesafen, não sofrendo interferência a ponto de retardar seu desenvolvimento. Para o diclosulam, em ambas as modalidades de aplicação, não foram constatados sintomas de intoxicação nas plantas de soja.

O estudo das características de produção é muito importante nas pesquisas, pois elas constituem os fatores realmente almejados pelos produtores ao final da safra (Durigan, 1983). As características mais importantes são: acamamento de plantas, altura de inserção da primeira vagem, número de vagens por planta, classificação de grãos por peneiras, massa seca de 100 sementes e produtividade. Embora não faça parte das características de produção, nota-se que a cobertura vegetal proporcionada pela comunidade infestante no momento da colheita pode demonstrar o grau de dificuldade para a colheita mecanizada, além de refletir o potencial de interferência mantido até o final do ciclo da cultura.

A presença de densas infestações de plantas daninhas pode afetar negativamente várias características de produção. $\mathrm{O}$ número de vagens para ambos os cultivares foi, em média, de 23 por planta, não havendo interferências negativas promovidas pelas plantas daninhas. O mesmo ocorreu para a altura de inserção da primeira vagem, na qual houve apenas diferença estatística entre os cultivares. O Monsoy 6101 apresentou-se, em média, com 0,24 m de altura, e o Coodetec, com 0,20 m.

Nota-se, na Tabela 4, que a baixa densidade das plantas daninhas não foi capaz de afetar negativamente a porcentagem de grãos retidos na peneira de número 16 . No entanto, na peneira de número 15 verificou-se a interferência das plantas daninhas, apresentando maior porcentagem de sementes de menor diâmetro na testemunha infestada, embora não diferencie da testemunha no limpo. Constatou-se, ainda, maior porcentagem de grãos com maior diâmetro para o cultivar Monsoy 6101 .

Devido ao maior porte do cultivar Monsoy 6101, constatou-se maior porcentagem de acamamento, atingindo $18,7 \%$ na testemunha mantida no limpo, enquanto para o Coodetec 206 foi de 5,7\%. Na testemunha infestada atingiu-se $47,9 \%$ de cobertura vegetal sem, no entanto, alterar a porcentagem de acamamento do cultivar Coodetec 206. O mesmo não foi observado para o cultivar Monsoy 6101, que, em razão do seu maior porte, se mostrou mais sensivel ao acamamento quando na presença das plantas daninhas.

Quanto à massa de 100 sementes (Tabela 5), verificou-se interação significativa entre os fatores, mostrando haver maior peso nas sementes oriundas da colheita do cultivar Monsoy 6101. Também se constatou que esse 
Tabela 4 - Valores de F, coeficientes de variação (CV\%) e teste de Tukey aplicado às médias da porcentagem de cobertura vegetal, das porcentagens de grãos retidos nas peneiras de número 16 e 15 e da produção de grãos $\left(\mathrm{kg} \mathrm{ha}^{-1}\right)$, por ocasião da colheita da soja. Jaboticabal-SP, 2003-2004

\begin{tabular}{|c|c|c|c|c|c|c|}
\hline & Variável & Cob. Vegetal $(\%)^{1 /}$ & $\begin{array}{c}\text { Peneira } 16 \\
(\%)\end{array}$ & $\begin{array}{c}\text { Peneira } 15 \\
(\%)\end{array}$ & $\begin{array}{l}\text { MS de } 100 \\
\text { sementes }(\mathrm{g})\end{array}$ & $\begin{array}{c}\text { Produtividade } \\
\left(\mathrm{kg} \mathrm{ha}^{-1}\right)\end{array}$ \\
\hline \multirow{3}{*}{$\mathrm{F}$} & Cultivar (C) & $1,54^{\mathrm{ns}}$ & $11,14 * *$ & $52,93 * *$ & $2,03^{\mathrm{ns}}$ & $2,75^{\mathrm{ns}}$ \\
\hline & Manejo (M) & $72,85 * *$ & $1,65^{\mathrm{ns}}$ & $2,55 * *$ & $2,33^{\mathrm{ns}}$ & $1,94^{\mathrm{ns}}$ \\
\hline & $\mathrm{C} \times \mathrm{M}$ & $0,43^{\text {ns }}$ & $0,61^{\mathrm{ns}}$ & $1,99^{\mathrm{ns}}$ & $3,11 *$ & $1,28^{\mathrm{ns}}$ \\
\hline \multirow{2}{*}{ Cultivar (C) } & Coodetec 206 & $\begin{array}{l}19,8 \\
19,8\end{array}$ & $62,5 b$ & $27,6 a$ & & $2.619,5$ \\
\hline & Monsoy 6101 & 22,1 & $67,8 \mathrm{a}$ & $21,7 \mathrm{~b}$ & & $2.513,2$ \\
\hline DMS & & 3,7 & 3,2 & 1,6 & & 128,1 \\
\hline \multirow{5}{*}{ Manejo. (M) } & Test. no limpo & $5,7 c^{2 /}$ & 62,8 & $24,6 a b$ & & $2.586,8$ \\
\hline & Test. infestada & $47,9 \mathrm{a}$ & 62,8 & $26,9 \mathrm{a}$ & & $2.389,8$ \\
\hline & diclosulam & $10,3 \mathrm{c}$ & 66,7 & $23,8 \mathrm{ab}$ & & $2.623,5$ \\
\hline & fomesafen & $29,3 \mathrm{~b}$ & 65,8 & $24,7 \mathrm{ab}$ & & $2.607,3$ \\
\hline & glyphos. + diclos. & $11,3 \mathrm{c}$ & 67,8 & $23,1 \mathrm{~b}$ & & $2.624,4$ \\
\hline DMS & & 8,2 & 7,1 & 3,6 & & 284,8 \\
\hline $\mathrm{CV}(\%)$ & & 39,3 & 10,9 & 14,8 & 6,0 & 11,2 \\
\hline
\end{tabular}

1/ Dados transformados em ARC SENSQRT $(\mathrm{x}+1,0) ; \stackrel{2}{\text { / }}$ médias seguidas da mesma letra, numa mesma coluna, não diferem entre si pelo teste de Tukey $(\mathrm{P}>0,05)$.

cultivar sofreu maior interferência imposta pelas plantas daninhas na testemunha infestada, causando diminuição no acúmulo de massa seca nos grãos.

Apesar da pequena influência da presença de cordas-de-viola nas características de produção, pode-se afirmar que o controle das convolvuláceas é importante, pois trata-se de plantas que promovem problemas por ocasião da colheita, dificultando-a e às vezes inviabilizando-a, mesmo em baixas infestações. Segundo Durigan \& Hirata (1988), os prejuízos causados pelas plantas daninhas na cultura da soja dependem não só do grau de infestação, mas também das espécies presentes na área, que, além de provocarem decréscimo na produtividade, podem prejudicar a operação de colheita, devido ao embuchamento das máquinas e ao tempo adicional gasto pelo agricultor para recolocar a colhedora em condições de operar.

A cultura da soja foi implantada no intervalo de renovação do canavial e o manejo químico das convolvuláceas é importante, pois, mesmo em baixas infestações, podem se tornar um grande problema para a próxima cultura, devido ao aumento do banco de sementes na área. Com a adoção do sistema de cana crua, o não-manejo destas pode acarretar potencial interferência na colheita mecanizada, pois suas infestações tenderão a crescer, enquanto para algumas espécies, como as gramíneas, deverão diminuir.

A integração dos métodos químico e cultural no controle das convolvuláceas presentes neste experimento mostrou-se eficaz em ambas as modalidades de aplicação do diclosulam, possibilitando a diminuição no custo de aplicação sem problemas com o efeito residual do produto. Embora os cultivares de soja apresentem características semelhantes de produção, pode-se dizer que o Monsoy 6101

Tabela 5 - Desdobramento da interação significativa para a massa de 100 sementes (g), considerando-se os manejos e cultivares de soja estudados Jaboticabal-SP, 2003-2004

\begin{tabular}{|l|c|c|}
\hline \multirow{2}{*}{ Manejo } & \multicolumn{2}{|c|}{ Massa seca de 100 sementes (G) } \\
\cline { 2 - 3 } & Coodetec 206 & Monsoy 6101 \\
\hline Testemunha no limpo & 14,11 a B & $15,19 \mathrm{ab}$ A \\
\hline Testemunha infestada & 14,50 a A & 14,13 b A \\
\hline diclosulam & 14,93 a A & $15,35 \mathrm{ab} \mathrm{A}$ \\
\hline fomesafen & $15,20 \mathrm{a}$ A & $14,52 \mathrm{ab}$ A \\
\hline glyphosate + diclosulam & $14,61 \mathrm{a} \mathrm{B}$ & 15,57 a A \\
\hline DMS (5\%) & \multicolumn{2}{|c|}{1,24} \\
Manejo dentro de cultivar & \multicolumn{2}{|c|}{0,89} \\
Cultivar dentro de manejo & \multicolumn{2}{|c|}{} \\
\hline
\end{tabular}

Médias na mesma linha, seguidas de letras maiúsculas iguais, e na mesma coluna, seguidas de letras minúsculas iguais, não diferem entre si pelo teste de Tukey $(\mathrm{P}>0,05)$.

Planta Daninha, Viçosa-MG, v. 24, n. 1, p. 91-98, 2006 
apresentou-se mais adequado para utilização dentro do período de renovação dos canaviais, pois atingiu o estádio $R_{8}$ (colheita) nove dias antes. Essa antecipação torna-se importante no momento do planejamento da implantação do novo canavial.

\section{AGRADECIMENTOS}

Ao técnico agrícola Gilson José Leite, funcionário do Dep. de Fitossanidade da FCAVUNESP, pelo apoio na execução do trabalho; à FAPESP, pelo apoio financeiro; e ao Sr. José Antônio Rossato e família, pela concessão da área experimental e por não medir esforços para viabilizar o trabalho.

\section{LITERATURA CITADA}

AZÂNIA, A. A. P. M. et al. Interferência de palha de cana-de-açúcar (Saccharum spp.) na emergência das espécies de plantas daninhas da família

Convolvulaceae. Planta Daninha, v. 20, n. 1, p. 207-212, 2002.

BANZATO, D. A.; KRONKA, S. N. Experimentação agrícola. Jaboticabal: FUNEP, 1989. 247 p.

BRASIL. Ministério da Ciência e Tecnologia. Legislação: decreto $\mathrm{n}-4.074$ (de 04.01.2002) que regulamenta a lei no 7.802 (de 11.07.1989). Disponível em: <http:// www.mct.gov.br>. Acesso em: 30 ago 2005.

BRASIL. Ministério da Agricultura. Secretaria Nacional de Defesa Agropecuária. Regras para análises de sementes. Brasília: 1980. $188 \mathrm{p}$.

CORREIA, N. M.; DURIGAN, J. C. Emergência de plantas daninhas em solo coberto com palha de cana-de-açúcar. Planta Daninha, v. 22, n. 1, p. 11-18, 2004.

DURIGAN, J. C. Matocompetição e comportamento de baixas doses de herbicidas, na cultura da soja (Glycine max (L.) Merril). 1983. 163 f. Tese (Doutorado em Solos e Nutrição de Plantas) - Escola Superior de Agricultura "Luiz de Queiroz", Piracicaba, 1983.
DURIGAN, J. C.; HIRATA, M. A. K. Efeito do controle de plantas daninhas sobre a quantidade e qualidade da produção de soja (Glycine max). In: CONGRESSO DE LA ASOCIACIÓN LATINOAMERICANA DE MALEZA, 9., 1988, Maracaibo. Resumenes... Maracaibo: Asociación Latinoamericana de Maleza, 1988. p. 54.

DURIGAN, J. C.; TIMOSSI, P. C.; LEITE, G. J. Controle químico da tiririca (Cyperus rotundus), com e sem cobertura do solo pela palha de cana-de-açúcar. Planta Daninha, v. 22, n. 1, p. 127- 135, 2004.

\section{EMPRESA BRASILEIRA DE PESQUISA}

AGROPECUÁRIA - EMBRAPA. Sistema brasileiro de classificação dos solos. Brasília: EMBRAPA-SPI, Centro Nacional de Pesquisa de Solos, 1999. 412 p.

EUROPEAN WEED RESEARCH COUNCIL - EWRC. Report of the $3^{\text {rd }}$ and $4^{\text {th }}$ meetings of EWRC. Comittee of methods in Weed Research. Weed Res., v. 4, p.88, 1964.

FEHR, W. L.; CAVINESS, C. E. Stages of soybean development. Ames: Iowa State University, Cooperative Extension Service, 1977. 11 p. (Special Report, 80).

MARTINS, D. et al. Emergência em campo de dicotiledôneas infestantes em solo coberto com palha de cana-de-açúcar. Planta Daninha, v. 17, n. 1, p. 151-161, 1999.

PITELLI, R. A.; DURIGAN, J. C. Ecologia das plantas daninhas no sistema de plantio direto. In: DIAZ ROSSELlO, R. (Coord.). Siembra directa en Cono Sur. Montevideo: PROCISUR, 2001. p. 203-210.

RODRIGUES, B. N. et al. Influência da cobertura do solo na eficiência de herbicidas residuais misturados com dessecantes em cultivo de soja. In: CONGRESSO BRASILEIRO DA CIÊNCIA DAS PLANTAS DANINHAS, 23., 2002, Gramado. Resumos...Gramado: SBCPD/ Embrapa Clima Temperado, 2002. p. 365.

RODRIGUES, B. N.; ALMEIDA, F. L. S. Guia de herbicidas. 5.ed. Londrina: Livroceres, 2005. 592 p.

SILVA, J. R. V.; COSTA, N. V.; MARTINS, D. Efeito da palhada de cana-de-açúcar na emergência de Cyperus rotundus. Planta Daninha, v. 21, n. 3, p. 375-380, 2003.

TIMOSSI, P. C.; DURIGAN, J. C. Doses reduzidas de fluazifop-p-butil + fomesafen no controle de plantas daninhas na cultura da soja. Planta Daninha, v. 20, n. 3, p. 439-447, 2002. 